\title{
The theory of agency and breastfeeding
}

Article

Accepted Version

Ryan, K., Team, V. and Alexander, J. (2017) The theory of agency and breastfeeding. Psychology \& Health, 32 (3). pp. 312-329. ISSN 1476-8321 doi:

https://doi.org/10.1080/08870446.2016.1262369 Available at https://centaur.reading.ac.uk/68322/

It is advisable to refer to the publisher's version if you intend to cite from the work. See Guidance on citing.

To link to this article DOI: http://dx.doi.org/10.1080/08870446.2016.1262369

Publisher: Taylor \& Francis

All outputs in CentAUR are protected by Intellectual Property Rights law, including copyright law. Copyright and IPR is retained by the creators or other copyright holders. Terms and conditions for use of this material are defined in the End User Agreement.

www.reading.ac.uk/centaur

\section{CentAUR}

Central Archive at the University of Reading

Reading's research outputs online 


\section{The Theory of Agency and Breastfeeding}

Kath Ryan ${ }^{1}$, Victoria Team ${ }^{1}$, and Jo Alexander ${ }^{2}$

${ }^{1}$ La Trobe University, ${ }^{2}$ University of Bournemouth

Kath Ryan, School of Nursing and Midwifery, La Trobe University

Kath Ryan is now at School of Pharmacy, University of Reading, UK

Victoria Team, School of Nursing and Midwifery, La Trobe University

Victoria Team is now at the School of Social Sciences, Monash University

Jo Alexander, previously School of Health and Social Care, University of

Bournemouth

The first two authors contributed equally to this paper and are to be regarded as first co-authors.

This work, funded by Bournemouth University, was conducted in collaboration with the Health Experiences Research Group, University of Oxford. We thank the women participants, whose stories appear on the website www.healthtalk.org, and members of the advisory panel who helped with recruitment and reviewed findings.

Correspondence concerning this article should be addressed to Kath Ryan, School of Pharmacy, University of Reading, Whiteknights, PO Box 226, Reading RG6 6AP, UK. Phone: +44118 3788818 Fax: +44118 3784703 Email: k.m.ryan@ @eading.ac.uk 


\begin{abstract}
Objective: In this paper we apply psychological agency theory to women's narratives of their breastfeeding experiences to understand the role of agency in relation to breastfeeding initiation, maintenance and duration.

Design: Qualitative, narrative, video interviews were collected from 49 women in the UK from a wide range of ethnic, religious, educational and employment backgrounds about their breastfeeding experiences. We undertook secondary analysis of the data focusing on their accounts of vulnerability and agency.

Findings: Women's agency was impacted by a variety of factors including their own vulnerability, knowledge, expectations and experience, the feeding environment and the support of health professionals in sharing decision-making and dealing with uncertainty. Conclusion: Health professionals as co-agents with women are well positioned to maintain, enhance or restore women's sense of agency. Breastfeeding goals should be included in women's birth plans. Training related to agency, continuity of care, and staffing and workload management supported by national breastfeeding policies could improve breastfeeding rates and experiences.
\end{abstract}

Keywords: agency, breastfeeding, experiences, health, midwifery, support 


\section{Introduction}

In many Western countries, the benefits of breastfeeding (such as "protection against infections and malocclusion, increases in intelligence, and probable reductions in overweight and diabetes" in infants and improved birth spacing, protection against breast and possibly ovarian cancer and Type 2 diabetes in mothers) are insufficiently recognised (Victora et al., 2016, p. 475). In high income countries, unfortunately, breastfeeding is no longer the norm (Rollins et al., 2016). In the UK, breastfeeding is promoted and supported by a number of international and government initiatives. The WHO/UNICEF ‘Baby Friendly Initiative' (BFI) was launched in the UK in 1994 to support the implementation by maternity care facilities of the Ten Steps to Successful Breastfeeding (UNICEF, 2010). Despite these initiatives and the fact that most mothers start breastfeeding and wish to continue (McAndrew et al., 2012), rates at 3, 6 and 12 months are still low compared to many other western countries (Oakley, Renfrew, Kurinczuk, \& Quigley, 2013). Beake (2010) reported that women in England were greatly dissatisfied with and had limited expectations of the level of breastfeeding and other support provided for them postnatally (Beake, Rose, Bick, Weavers, \& Wray, 2010). These findings are not unique to the UK: studies investigating women's and staff members' hospital experiences of breastfeeding in other developed countries reported similar findings (Brown, Davey, \& Bruinsma, 2005; Declercq, Labbok, Sakala, \& O'Hara, 2009; Hildingsson, 2007; Rayner, Forster, McLachlan, Yelland, \& Davey, 2008; Schmied, Cooke, Gutwein, Steinlein, \& Homer, 2009). This suggests that lack of advice and practical support provided to women by hospital staff might shape their breastfeeding experiences including sense of self and agency and thereby influence their related decisions. There are few studies that specifically discuss agency in relation to breastfeeding initiation, maintenance and duration in term infants although issues are sometimes discussed in terms of empowerment and selfdetermination. 


\section{Agency, Health and Breastfeeding}

Before discussing agency in relation to breastfeeding it is necessary to give a brief overview of the development of agency as a concept in health in general. Prior to the 1970s a paternalistic model of doctor-patient communication was predominant. Then in the early 1970s, in line with neoliberalism, the role of health professionals in terms of agency and autonomy was reconsidered (Salmon, White, \& Feinglass, 1990). A shared decision-making approach emerged (Emanuel \& Emanuel, 1992) and paternalism was considered acceptable only in emergency situations. With equality of roles, agency has taken the form of a partnership (Langer, Schröder-Bäck, Brink, \& Eurich, 2009). Patients are now more autonomous, often exercising their own agency rather than relying on a health professional (Edwards \& Elwyn, 2009). This shift towards self-care agency relates to reduced information asymmetry attributable to improved health literacy and computer skills, easy access to health information, and people's empowerment to take a leading role in self-management (McMullan, 2006).

Sense of agency is defined as a person's 'ability to refer to oneself as the author of one's own actions' (de Vignemont \& Fourneret, 2004, p. 2). Self-care agency is defined as the capacity of an individual to engage in self-care behaviours, including the ability to initiate, perform and maintain self-care practices focused on maintaining life, healthy functioning and improved wellbeing (Sidani, 2011, p. 81). Many of these practices might require the coordinated action of more than one agent (Rodney, Brown, \& Liashenko, 2006). Since many people do not have control over social or organisational practices a proxy agent, such as a health professional or family member, might be required to achieve the desired outcome (Bandura, 1997). Agency relationship occurs when one party acts on behalf of another (Shapiro, 2005) and is characterised by information asymmetry, inevitably related to professional knowledge, skills and power (Maynard \& Bloor, 2003). With respect to health, 
the agency relationship has frequently been attributed to 'health professional-patient communication' in primary care settings, where health professionals have been traditionally viewed as agents of patients' health care and social control (Morgan, 1997). Studies linking enhanced sense of agency with improved emotional wellbeing, sense of control and improved self-management largely relate to cancer survivorship (e.g. O'Hair et al., 2003) and chronic disease management (e.g. Sousa, Zauszniewski, Musil, Price Lea, \& Davis, 2005).

In relation to breastfeeding, agency theory has been applied to women's choice either to breastfeed or not. Bartlett (2003) highlighted the societal expectation that a woman will make the 'right,' culturally defined choice to breastfeed. She further argued "because 'failure' to choose breastfeeding subjects women to various judgements their agency is always already diluted" (p. 156). She criticized past and current forms of governmentality as limiting women's agency despite the available consumer options. Kukla (2005) argued that the mother's independent agency is erased from the outset.

In moral agency theory, moral action is linked to moral knowledge and moral reasoning around notions of right, wrong and accountability. Author et al (2010), however, explored moral work on the self (individual actions rather than adherence to moral codes) in relation to breastfeeding and concluded that "women's embodied experience and sense of self are disciplined within current, limited, often punishing discourses" (p. 951), for example, around organisational and self-care postnatal practices. This work stopped short of applying agency theory.

Schmied and Lupton (2001) discussed losing maternal self and agency and women's perceptions of themselves as their infant's person (p. 241). Sweet (2008) noted that 'good' parenting and breastfeeding were synonymous and that mothers of preterm infants were faced with conflicting ideas (p. 5). On the one hand, a woman's inability to feed her baby at her breast affected her sense of agency as a mother, while on the other, milk expression and 
expressed breast milk feeding connected her to her infant and allowed her to restore it. In addition, according to Sweet (2008), women who focused only on benefits for the baby - 'a good parent always puts the child first' - were denying their own agency (p. 5).

In this article, we define agency as a woman's ability to make a decision, to work towards her breastfeeding goals, to identify and express her needs, and to seek and receive timely, appropriate help. We develop this construct of agency in relation to breastfeeding from women's narratives of their breastfeeding experiences in the UK. We acknowledge that women who decided not to breastfeed also had complex needs which, if unmet, diminish their sense of maternal agency, however, we will not focus on them in this paper.

\section{Methods}

The purpose of our qualitative study was to understand women's experiences of breastfeeding and their related information and support needs in the UK. The interviews are held in the archive of the Health Experiences Research Group, University of Oxford, and summarised findings, illustrated by video clips, are disseminated on the freely available website www.healthtalk.org. Forty-nine face-to-face, in-depth interviews with women who were currently breastfeeding or had breastfed within the previous two years were conducted in 2005-6. The data have been updated approximately every two years with new interviews added in 2015 to keep the site relevant to the current breastfeeding situation in the UK. Participants were recruited via health professionals, breastfeeding advocates (such as La Leche League, the Association of Breastfeeding Mothers, The National Childbirth Trust), members of an expert Advisory Panel, and the Healthtalk website to obtain maximum variation in experiences and demographics. Ethical approval was obtained from the UK Eastern Multi Region Ethics Committee. Informed consent and copyright to the video material were obtained from participants prior to interviews. 
Participants ranged from 19 to 40 years in age and were from different ethnic (White and Black British, Bangladeshi British, Colombian, French, Indian, Pakistani, Sri Lankan, Thai, Ugandan), religious (Christian, Jewish, Muslim, Hindu, Buddhist) and socioeconomic backgrounds, various educational levels (no qualifications through to postgraduate degrees), employment status (unemployed, maternity leave, self-employed, paid employment) and marital status (married, single and co-habiting). They resided in England, Scotland, Wales and Northern Ireland. They had a wide range of breastfeeding experiences including early weaning, difficulties, ease, long-term feeding, tandem feeding, multiple babies, ill babies, and personal illness.

Interviews took 35-90 minutes excluding time for breaks required for infant care. All interviews were conducted in English by the first author and were video and/or audio recorded. They were conducted in the women's homes in all but one case. The interviews were unstructured, ensuring that participants provided their own accounts of their breastfeeding experiences as they preferred to tell them with limited interruption from the interviewer. The participants were asked to tell the story of their breastfeeding experiences and further prompted to reflect on any particular issues raised. The conversation like interviews produced the women's narratives as a co-creation.

All interviews were transcribed in full and coded thematically, using NUDIST software for data management and the constant comparison method for analysis (Pope, Ziebland, \& Mays, 2000). Brief thematic summaries with illustrative video, audio and written clips of issues raised are displayed on the internet (www.healthtalk.org).

In this article, we present our secondary analysis (Heaton, 2004) of the data to focus on what the women said about their early experiences with breastfeeding. Engagement with the data indicated some women's postnatal vulnerability, so we again used thematic analysis and constant comparison through the lens of agency theory to understand women's attempts 
to achieve their breastfeeding goals and practices and what impeded or enhanced their sense of agency. This resulted in three themes: Agency and support; Loss of agency: Vulnerability; and Ensuring agency: Sharing the role of breastfeeding agent. These themes and associated subthemes include examples of women exercising, losing and reclaiming their sense of agency in their breastfeeding practice. They also allude to what sharing the role of breastfeeding agent and decision-making with health professionals might look like.

\section{Findings}

Women's sense of agency was influenced by various factors, including but not limited to their prior knowledge, experience and skills, and their physical/health capacity to meet their goal to breastfeed. Most of the participants acknowledged that they required some sort of help in the perinatal period from one or more health professionals as their breastfeeding support agent. They required consistent information and explanation, advice, and emotional and physical support. Even participants who did not experience any difficulties with breastfeeding expressed their desire to be re-assured that they were breastfeeding correctly. They explained that confidence brought a sense of satisfaction and the realisation that they could breastfeed.

\section{Agency and support}

Many participants acknowledged various types of support provided by health professionals that enabled them to achieve their agency goal and, conversely, practices that hindered. The theme of agency and support incorporates the subthemes of 'agency and (lack of) support' and 'restoring lost agency'. Accounts varied according to whether the women viewed health professional input as facilitating or inhibiting their sense of agency. One-to- 
one support provided by a maternity nurse at night helped one participant to establish and possibly even maintain her breastfeeding:

There was a nurse on that ward who helped me through the night and I have a feeling that was one of the things that really just cemented what we were doing... when things were really ever so quiet, she just took me through on a one-to-one... I think that was very helpful and, who knows, it may have helped me to carry on for as long as I have. [37 year-old, first time mother]

Breastfeeding was delayed for another woman whose daughter required heart surgery immediately after birth. "I knew that the only thing I could do for her was to express, so I did. I expressed and expressed and expressed and expressed, gallons of it" was how she explained her goal-directed actions. She acknowledged the physical and emotional support initially provided by a midwife:

I was lying on the bed, I was expressing on the one side by hand, the midwife was expressing on the other side and trying to suck off the colostrum with a syringe desperate to give my baby what she needed. It was incredibly hard work, but we chatted, and we laughed. [32 year-old mother of two]

In contrast, a 39-year-old woman, whose second child was diagnosed with Down's syndrome, considered herself the sole agent of her daughter's feeding. Because she was born at home they "managed to escape all that kind of hysteria at the beginning ... and keep away from too much interference" such as the insertion of a nasogastric tube that would have been required with an early diagnosis in hospital. Confident in her ability to latch a baby onto her breast and to produce sufficient milk, when breastfeeding wasn't going well she knew that the difficulties were related to her daughter's health condition not her inability to breastfeed. Agency and (lack of) support 
Lack of support, inappropriate support and lack of continuity of care, including contradictory advice, provided by health professionals undermined women's sense of agency. For example, one woman explained how lack of support provided by hospital staff shaped her early breastfeeding experience with her second child:

I was told by all the breastfeeding people that [inverted nipples] wouldn't be a problem and that the hospital staff would help me latch on. So I just put my trust in the hospital staff... A lady came to see me [and] said if I needed anything to ring the bell. I rang, I rang, rang, rang and rang, and because they were busy and there were babies and mums that were in more need, and all I wanted was to be latched on they put me as a low priority. I had to wait 'till four o'clock in the morning. I was in tears because I was in so much pain... trying to get the nurse's attention, no-one came and... I knew that by this point I just wanted to go home, I knew that I wasn't particularly well latched on, but I didn't care, I just wanted to go home. [26 year-old mother of three]

Similarly, inappropriate advice resulted in women's loss of agency. One woman eloquently described the contrast between two experiences in different environments: I believe that I was given some wrong advice. I was in a large hospital, where the midwives don't have much time, and I asked for some advice, and I was told to [use a cradle hold but that] was obviously not the right thing because it was painful [for him]... Within the first twenty-four hours I transferred to another hospital which is a small cottage hospital and they helped me a great deal ... I feel misinformed, just through the other person's lack of knowledge. I was just relieved that I was somewhere where I did feel that they were very supportive and they were giving me the correct information. [22 year-old first time mother] 
Enforced infant latching by some midwives, described by several women, robbed them of their agency and decreased their confidence in their ability to learn to breastfeed correctly:

"The midwife ... literally lifted up my breast and sort of shoved it [laughs] in the baby's mouth". [27 year-old mother of three]

Lack of continuity of care resulted in a variety of suggestions and advice being provided by different health professionals as they offered women alternatives but it often left women feeling confused and unsure about their ability to meet their breastfeeding goals.

Doubt and uncertainty undermined their sense of agency.

So midwives were coming and going, and in my experience... everyone will show you a different way to breastfeed. There was no continuity. [31 year-old first time mother]

\section{Restoring Lost Agency}

Several women described retrieving their sense of agency by taking matters into their own hands and becoming sole agents for their breastfeeding goals. Self-discharge is arguably the strongest thing a woman can do to restore her sense of agency. A few women did exactly this but several others spoke about wanting to go home. The 26 year-old mother of three quoted above lost trust in health professionals as her breastfeeding supporters and health care agents to such a degree that she decided to discharge herself from the hospital early despite experiencing difficulties with latching.

A 19 year-old first-time mother, discharged herself from the hospital and went home to learn to breastfeed. She received very little help from hospital staff, her infant was given formula without her permission and she felt patronised by a health professional who made her feel that she had to breastfeed or she would be seen as a bad mother:.

It was really horrendous. The way they treat the women in that hospital was disgusting. Well, I had problems with a lot of leaking with my breasts and instead of 
showing me what I can do and how to help me they just left me to sleep in a soaking bed the whole night. So, I left the next day. [23 year-old mother of two] Restoring agency might be a one-off action, such as self-discharge, or it might be a series of actions continued well into the postnatal period. One woman came from an area where breastfeeding was not very popular - someone even told her that it was not natural. Her fight to restore her agency started in hospital:

So the first time the midwife attached [my daughter] for me it just felt like I was a bystander watching, this woman kind of shoved my baby on my breast ... I didn't like that. I'm quite self-conscious and I didn't like people messing with my breasts and things... but I couldn't do it in front of them. I was shaking and I was nervous and a newborn doesn't know how to feed and you don't know how to feed. You've got to learn together... and so I went home and I sorted it out myself, just sat in bed with my baby and spent some time getting to know her and just doing it at our own pace with no one watching, so that we could mess it up and it didn't matter. [26 year-old first time mother]

She lost contact with the friends that she had before she became pregnant 'because they think it's a bit strange breastfeeding [and being] tied to a baby', but made new friends through breastfeeding and other support groups that she attended regularly. She also used the internet for information about breastfeeding and to join web-based mothering chat rooms. She found herself under pressure from various quarters to introduce a bottle, to have her baby weighed regularly, to introduce solids, to get her baby to sleep through the night and, as a single mother, to go back to work. She resisted the pressure by having 'faith in breastfeeding' and just doing what felt right for her and her baby. In time she went from receiving peer support and encouragement to being able to offer them to other women. Hers is a story of assumed vulnerability by health professionals and others and ongoing restoration of agency. 
This woman's narrative also illustrates how 'support' that is perceived as surveillance can inhibit agency and that withdrawing from the surveillance restores it.

\section{Loss of agency: Vulnerability}

Vulnerability and loss of agency were influenced by unrealised (and unrealistic) expectations, such as following a difficult or traumatic birth, unexpected difficulties with breastfeeding initiation, and lack of timely, consistent, appropriate advice. Vulnerability was increased by the unfamiliar hospital environment.

\section{Expectations versus reality}

Some women had expectations that breastfeeding would be an 'easy' process 'naturally' following on from their initial decision to breastfeed. New and strange experiences, however, and later uncertainty about their ability to breastfeed or to produce sufficient milk decreased their sense of agency and created vulnerability.

The box was always ticked with me: yes, she's going to breastfeed, so I really thought that there was not going to be a problem at all... To be quite honest it wasn't really [an issue] until after the baby was born and when [I] felt that I needed the information because things were going wrong. [38 year-old first time mother]

After giving birth, some women felt exhausted and traumatised and, at the same time, they experienced pressure (internal and external) to breastfeed. Their feeling of being out of control created vulnerability.

I wasn't feeling the best, and I just felt very pressurised, people had been saying, "You have to do this [latch] quickly, if you don't do it quickly it's not going to work. If you don't latch on quick enough, your baby might struggle later on to feed". [31 year-old first time mother] 
The hospital environment was described by many women as strange, busy, stressful, unfriendly and lacking in privacy. Some felt ignored, powerless, unimportant, and homesick. One participant, who had an unplanned caesarean section, was particularly alienated by the operating theatre, the surgical delivery and the anaesthetics she received, and seeing her husband in theatre dress. She had no opportunity for skin-to-skin contact with her infant, and a paediatric check-up prior to breastfeeding made her feel very vulnerable. She lacked agency and struggled with breastfeeding for the first six months requiring the support of a lactation consultant.

I was just so upset and distressed by the fact that I' $d$ been taken into theatre... All the things that in my mind I had envisaged would happen, the baby being brought up to my chest, my husband being there with me, you know, just the experience of three people that I knew really well and it wasn't like that... and this whole environment, it just felt this wasn't what I had wanted. [38 year-old first time mother]

The hospital environment, care system and social order made some women feel that they were not important and their breastfeeding issues were insignificant compared to the needs of other people. This prevented them from exercising their agency to obtain the help they needed.

I was left then on my own and, I think, I should have perhaps been a bit more assertive and gone and said "Can you come and just check that I'm doing it correctly" ...I tend to not want to bother anybody really and just think "Well they've got other babies to see to, and I'm not the only one here". [23 year-old first time mother] Some women complained about their lack of privacy in the hospital and of feeling controlled and supervised, particularly with milk expression. Surveillance deprived them of their agency. They wanted to go home, where they could manage breastfeeding and milk expression on their own. Other women, having difficulties with breastfeeding and receiving 
insufficient support from the hospital staff, looked forward to being discharged and getting home where they expected to have more support.

I wouldn't say the midwives in the hospital were overly supportive [with] feeding to start off. The first twenty-four hours with any of my children have never been the easiest time but once you're at home and you've got more support... that's when it definitely became a bit easier. [27 year-old mother of three]

One midwife's inappropriate comment to this same woman had the effect of decreasing her confidence rather than helping her to solve her problem and left her feeling unsupported, inadequate and unagentic:

I was only young, so I think that nobody really expected me to want to breastfeed anyway, so I didn't get as much support as I would've hoped. There was one occasion during the first night, when I was hoping to be discharged the next morning and the midwife said that, if I couldn't feed the baby for half an hour they wouldn't let me go in the morning. So, I was a bit worried about that... I think she wanted me to give the baby a bottle. She kind of made me feel inadequate... I think, in her eyes, she was doing me a favour... I don't think that she was supporting me to do what I wanted to do at the time. [27 year-old mother of three]

Similarly, another woman lost her sense of agency by not understanding the problem and believing that she was the reason for her preterm daughter staying in hospital:

I can remember breaking down in front of the doctor one day and being very upset and [him] saying "What's the problem?" and "You're not going to let me take her home until I can breastfeed properly." He said "No, that's not the case at all. She goes home when she's ready to go home. We would just encourage you to breastfeed because it's better for her". [32 year-old first time mother] 


\section{Ensuring agency: Sharing the role of breastfeeding agent}

Health professionals are usually considered as both maternal and infant agents, who provide support with breastfeeding, help women to meet their goals and ensure that babies are adequately fed. Breastfeeding women, however, also perceived themselves as their infant's agent. Participation in shared decision-making ensured women's agency.

In this study, most women were willing and able to participate in shared decisionmaking in relation to breastfeeding issues. They felt their lack of voice when shared decisionmaking was overridden. For example the midwife's paternalistic approach rather than an explanation of the benefits of the nipple shields in this woman's situation did nothing to help her sense of agency.

A midwife came out and said "You're going to have to use shields". And I burst into tears and said "But I did this with my daughter. I had a nightmare. Please you've got to help me." And she said "Look we're too busy - it's a shield or nothing." [26 yearold mother of three]

The midwife's willingness to aggress against the agency of this mother was influenced by a lack of time. The approach she used doubled this woman's vulnerability: her struggle to breastfeed and her lack of voice in her attempts to achieve her goal. In contrast, a later discussion with a lactation consultant acknowledging the side effects of nipple shields and pointing out that their use was not ideal but probably inevitable in her circumstances enabled her to restore her sense of agency.

Similarly, another participant described her feelings of exclusion from shared decision-making on the method used for breast milk expression:

It was the midwives that decided really for me to [express breast milk] by electric pump. I think perhaps if I'd done it by hand for the first couple of days, perhaps it 
would have been a bit better...I don't express very much now either. I don't enjoy it at all, I find it painful. [23 year-old first time mother]

Another participant revealed her feelings of anger and annoyance after a difficult birth at a paediatrician's management plan that contradicted her own:

I just do worry that the paediatricians think about the baby's health first, but not the long term problems with the mother and feeding. And I mean giving formula on the first night I thought was a bit crazy... I was expressing lots of colostrum, and I thought that would have been enough really. I was a bit annoyed about that. [30 yearold mother of two]

In the excerpt above, health professionals appeared focused solely on the infant and did not see the issue from both maternal and infant perspectives. They became engulfed in their role as agents of infant feeding ignoring their duty to also support a woman to attain her breastfeeding goals and thus to restore her damaged sense of agency.

Several women talked about the early introduction, by hospital staff, of formula milk without prior discussion or maternal agreement and how exclusion from shared decisionmaking related to their loss of agency.

[One] midwife said "Oh she was hungry last night, and we didn't want to wake you up, so we gave her formula milk"... I was very angry 'cause I'd put in my birth plan that I wanted her to have no formula milk but this was one midwife who wasn't particularly supportive of breastfeeding. [38 year-old mother of two] Conversely some women complained about the 'pressure' to breastfeed that was put on them by some health professionals. When they were already struggling to breastfeed this deepened their sense of inadequacy and contributed to the loss of agency. In contrast, women who were given a choice and involved in decision-making or allowed space and time to work things out had positive breastfeeding-related experiences in hospital. 


\section{Discussion}

Limiting discussion of women's agency to their choice to breastfeed oversimplifies the complexity of the breastfeeding process and the meaning of agency related to it. Our findings show the psychosocial nature of agency in relation to breastfeeding that exists within complex social, cultural and environmental constructs (Leeming, Williamson, Lyttle, \& Johnson, 2013). The hospital is already an unfamiliar and sometimes hostile place in which many women feel disempowered, alienated and vulnerable (Dykes, 2006), so the type of support received there significantly impacts their sense of agency. Support from health professionals aimed at maintaining or restoring women's sense of agency, decreasing doubt and uncertainty, and enabling them to make informed decisions related to their breastfeeding practice, including problem solving, has the ability to alter experience, confidence and goal achievement. Conversely, unrealistic expectations, lack of knowledge, doubt and support viewed as pressured, paternalistic, patronising or supervisory dispossess women of their agency.

\section{Sharing agency}

Shared agency has been described as rational cooperation towards a shared goal, requiring shared action and joint commitment and the assumption that both agents have equal authority (Gilbert, 2006, p. 8). Shared agency has advantages over individual agency because two or more agents may act towards the shared goal in different ways. Moreover, collective effort and cooperation of co-agents increases the probability of success (Bandura, 2000). Some health professionals might position themselves as sole agents or as co-agents but with greater power. This approach decreases women's sense of agency, as we have demonstrated above. Theoretically, women and health professionals as breastfeeding agents should each 
have the same power and control over the process, however, lack of time and sometimes lack of skills, structural and procedural barriers, and professional resistance can limit a health professional's role as an agent and result in insufficient or inappropriate action on their part. Schmied et al (2011) in a metasynthesis of professional and peer support proposed a continuum with helpful, facilitative, authentic presence (rapport with women that builds a trusting relationship) on one end, that we would call agency enhancing, to unhelpful, disconnected, reductionist encounters on the other that diminish women's agency.

Women's perception of shared agency can also influence the process of breastfeeding. Some women perceived health professionals as sole agents of breastfeeding and limited their own role to following health professionals' advice without verifying it. Others, having perceived themselves as a sole agent, lost their sense of agency as a result of health professionals' authoritative decision-making. The majority of women in our study, however, were clear about their breastfeeding goals and desired shared agency in achieving them.

The role of health professionals in relation to breastfeeding support is complex; they are maternal and infant agents/co-agents. Balancing mother and infant support is closely related to the concept of shared agency. For example, some health professionals, focusing almost solely on benefits to the infant, have pressured women to breastfeed even while they were unable to because of health problems (Rothchild, Van Cleve, Mumford, Claire, \& Johnson, 2016). In our study too, women raised their concerns regarding an inadequate balance of care when health professionals prioritized infants' needs and neglected women's needs. These actions were linked to women's loss of agency and confusion related to breastfeeding messages. It is important that health professionals address the needs of the mother-infant dyad because women themselves have found it difficult to balance their own and their infant's needs, for example in making decisions about medicine use during breastfeeding (McDonald, Amir, \& Davey, 2011). 


\section{Uncertainty and agency}

Theoretically, personal agency depends upon the level of expectancy to attain the desired outcome which is influenced by two factors - the degree of importance of it to the person and the degree of uncertainty inherent in the expectation of the outcome (Moran, 1993). The majority of women in our study decided during pregnancy to breastfeed because they viewed it as important, however, the importance of it to them was often undermined by subsequent experience and an already existing doubt about their ability to achieve their breastfeeding goal. Their doubt was further fuelled by the contradictory advice and actions of health professionals. The introduction of formula feeds, for example, made some of them doubt the correctness of the health promotion message that 'breast is best'. Lack of timely and appropriate support, and unilateral health professional decision-making resulted in women's loss of trust in them as co-agents, further jeopardising breastfeeding outcomes. Selfdischarge can be viewed as an act of restoring agency but it could also increase outcome uncertainty and thus further erode agency.

Researchers in the UK and other countries have reported high levels of inconsistent and contradictory advice related to infant feeding (Redshaw \& Henderson, 2012). Several health professionals offering alternative suggestions can be perceived by women as contradictory advice. Continuity of care might be one way of addressing this problem (Schmied, Beake, Sheehan, McCourt, \& Dykes, 2011). All recommended contemporary practices in maternity and infant care units in the UK are evidence-based and policygrounded which, if followed, should reduce contradictory advice and outcome uncertainty, although there is always going to be variance in interpretation and application to individual situations. Better explanation of these practices, better communication of all underpinning polices in lay-language and shared decision-making have the potential to reduce uncertainty 
and improve woman-health professional collaboration aimed at established breastfeeding as a shared goal.

People have become more health literate and autonomous, exercising their own agency rather than relying on a health professional (Edwards \& Elwyn, 2009). Focusing on their perceived sufficient knowledge and thinking that breastfeeding is easy and comes naturally (see also Williamson, Leeming, Lyttle, \& Johnson, 2012), some women initially view themselves as a sole agent in relation to infant feeding believing that they will not require any support. This stage, in the psychology literature is referred to as misidentification of the self as an agent (Pacherie, 2007). Women's later doubts and uncertainties about their ability to breastfeed, such as Will I produce enough milk? and Why isn't my baby settling?, Freud called counter-expectations and have been considered as aspects of failed agency (Moran, 1993). Failed agency, we would argue, is inherent in women's vulnerability and uncertainty such that violation of feelings and actions, unsupportive messages, inappropriate professional and self-judgements and failure to meet women's own emotional needs easily tip the agentic balance. What we have called failed agency, Thomson et al (2015) argued, leads to the creation of shame as a result of among other things 'undermining and inadequate support' (p. 40). Recognition of the factors that lead to failed agency could result in strengthening behaviours that prevent its occurrence.

Although managing uncertainty is considered a key element of professional-patient communication it is unclear, however, what elements of this communication are associated with desirable outcomes (Street Jr, Makoul, Arora, \& Epstein, 2009). Managing uncertainty and maintaining agency related to breastfeeding is even more complex and less researched. Many women in our study, even those who felt agentic and did not experience any breastfeeding-related problems, tended to question their ability to produce sufficient breast milk (Author et al, 2013). This issue has previously been reported both in the UK (Thomson, 
Dykes, Hurley, \& Hoddinott, 2012) and other countries (Avishai, 2007; Labiner-Wolfe, Fein, Shealy, \& Wang, 2008). Instructive idealistic educational messages, which are distant from women's actual experiences, could be one of the factors that create uncertainty (Hoddinott, Craig, Britten, \& McInnes, 2012). Management of uncertainty, including its relationship to agency, has not received adequate attention.

\section{Support and agency}

Our findings clearly illustrate the sort of health professional behaviours that enhance women's sense of agency - unhurried one-to-one time assisting a woman to learn to breastfeed; physical and emotional support, encouragement and confidence-boosting; personalised problem-solving; continuity of care; and shared decision-making. In contrast, health professional behaviours that leave women feeling vulnerable and voiceless include paternalism, surveillance, contradictory advice, pressure to breastfeed and adherence to hospital routines that are not woman-friendly. Other researchers (Burns, Fenwick, Sheehan, \& Schmied, 2012; Schmied et al., 2011) have stressed the importance of relationships in the breastfeeding encounter, between the mother and her baby and the mother and her health professional(s). Relationships are not built quickly during short hospital stays but can be developed over time when women receive continuous care through pregnancy, childbirth and into the postpartum period. Over ten years ago Dykes (2006) likened the maternity hospital to a 'production line' with mothers as suppliers of breast milk (p. 75) and midwives adopting 'a largely instrumental and managerial approach' (p. 153). If anything, with cuts in funding and services, increases in the birth rate and a shortage of midwives, the context of postnatal care is worse now than it was then (Ewers, 2014). We suggest that it is time for a complete rethink about how care is delivered, consciously ensuring that women's agency is preserved.

With the changed structure of modern families and the related loss of family-based, woman-to-woman support and, particularly, the medicalization of birth and the perinatal 
period, the importance of the role of health professionals in providing support and creating a caring and empathic learning environment has dramatically increased (Barclay et al., 2012). Support with breastfeeding initiation has traditionally been considered midwives' professional domain (Burns et al., 2012). Most women in our study appreciated health professionals' support that left their agency intact. Two systematic reviews (Britton, McCormick, Renfrew, Wade, \& King, 2007; Renfrew et al., 2009) on the role of health professionals in supporting breastfeeding women have acknowledged that tmely, consistent, appropriate, and problem-specific support, which takes into account an individual's situation, contributes to increased initiation and maintenance of breastfeeding.

Understanding of the components of health professional support that facilitate breastfeeding initiation and maintenance remains limited (Burns et al., 2012) and understanding of what constitutes agency in relation to breastfeeding is negligible. In addition to information provision, knowledge improvement and skills development, professional support also plays an important role in reducing uncertainty among breastfeeding women (Thomson et al., 2012), as our findings have indicated. Women's and midwives' lack of belief in women's ability to breastfeed and to a lesser extent in the importance of breastfeeding lead to doubt and uncertainty which mean that agency is already diminished. Training hospital staff has the potential to increase breastfeeding related knowledge and initiation rates in the hospital setting (Renfrew et al., 2009) but the environment is still not conducive to personal agency.

O'Brien et al (2009a) explored the psychological factors that influence the duration of breastfeeding and found the most important included "the mother's priorities and mothering self-efficacy, faith in breast milk, adaptability, stress, and breastfeeding self-efficacy” (p. 55) which we suggest, as our data show, all feed into sense of agency. The authors suggested a toolbox of coping strategies to assist with the challenges of breastfeeding in the early days, 
including increased breastfeeding knowledge, conscious efforts to relax and look after oneself, mindfulness and other strategies in line with cognitive behaviour therapy, namely positive self-talk, challenging unhelpful beliefs, active problem solving and goal setting (O’Brien, Buikstra, Fallon, \& Hegney, 2009b). These strategies, which might maintain or restore agency, could be taught to all pregnant women in antenatal classes and postnatal recognition of women at risk could trigger reinforcement. It is time to dispel the myth that breastfeeding is 'natural' and accept that, like any other human activity, it must be learned (Volk, 2009).

Health professionals, however, frequently limit the time spent on breastfeedingrelated interactions due to other priorities (Rayner et al., 2008). Time and resource shortages, and structural pressures have resulted in the adoption of a technocratic model of care which has alienated them from mothers (Davis-Floyd, 2001). Dykes (2006) argued that contemporary midwives have turned into 'shop-floor supervisors' of technologized processes, leaving no space for breastfeeding-related shared decision-making and responsibility, thus becoming sole agents of women's and infants' health. Our observation, as also described by Beake (2010), is that postpartum women can feel ignored and their breastfeeding needs can seem unimportant to them compared to the needs of other women. Postpartum women wish that health professionals allocated more time to support them with breastfeeding, prefer informal care and value patience, kindness and reassurance in contrast to over-enthusiastic promotion of breastfeeding and a problem fixing approach (Hoddinott, Craig, Britten, \& McInnes, 2010).

\section{Conclusion}

Previously agency as a psychological concept applied to breastfeeding practice has not been studied in depth. Using women's stories, we have reframed our understanding of 
breastfeeding practice in terms of agency. Breastfeeding agency begins before birth and is strengthened through knowledge, confidence, learning and experience. Breastfeeding goals should be part of every woman's birth plan with consistent, continuous support from someone they trust who has time to instil a belief in the importance of breastfeeding and their ability to do it, and assist with problem-solving when necessary. Agentic women might be more likely to breastfeed for longer and judge their breastfeeding experience as successful. It is therefore important to work towards ensuring that women are in control of their breastfeeding practice.

We have argued that health professionals, co-sharing with women the role of breastfeeding agent, are well positioned to maintain, enhance or restore women's sense of agency. This paper addresses agency from the women's perspective but similar work needs to be done from the perspective of health professionals. Policy implications from our findings include education to increase health professionals' awareness of the role of shared agency in initiating and maintaining breastfeeding and developing their related practical skills, continuity of care for perinatal women, and a review of staffing and workload allocations. We propose that this suggestion should be included in a UK National Breastfeeding Strategy. 


\section{References}

Author et al (2010)

Author et al (2013)

Avishai, O. (2007). Managing The Lactating Body: The Breast-Feeding Project and Privileged Motherhood. Qualitative Sociology, 30(2), 135-152. doi:10.1007/s11133006-9054-5

Bandura, A. (1997). Self-efficacy: The exercise of control New York, NY: Freeman.

Bandura, A. (2000). Exercise of Human Agency through Collective Efficacy. Current Directions in Psychological Science, 9(3), 75-78. doi:10.1111/1467-8721.00064

Barclay, L., Longman, J., Schmied, V., Sheehan, A., Rolfe, M., Burns, E., \& Fenwick, J. (2012). The professionalising of breast feeding-Where are we a decade on? Midwifery, 28(3), 281-290. doi:10.1016/j.midw.2011.12.011

Bartlett, A. (2003). Breastfeeding bodies and choice in late capitalism. Hecate, 29(2), 153165.

Beake, S., Rose, V., Bick, D., Weavers, A., \& Wray, J. (2010). A qualitative study of the experiences and expectations of women receiving in-patient postnatal care in one English maternity unit. BMC Pregnancy and Childbirth, 10(1), 70. doi:10.1186/1471$2393-10-70$

Britton, C., McCormick, F. M., Renfrew, M. J., Wade, A., \& King, S. E. (2007). Support for breastfeeding $\quad$ mothers (Review). Retrieved from http://apps.who.int/rhl/reviews/langs/CD001141ru.pdf

Brown, S. J., Davey, M.-A., \& Bruinsma, F. J. (2005). Women's views and experiences of postnatal hospital care in the Victorian Survey of Recent Mothers 2000. Midwifery, 21(2), 109-126. 
Burns, E., Fenwick, J., Sheehan, A., \& Schmied, V. (2012). Mining for liquid gold: midwifery language and practices associated with early breastfeeding support. Maternal \& Child Nutrition, no-no. doi:10.1111/j.1740-8709.2011.00397.x

Davis-Floyd, R. E. (2001). The technocratic, humanistic, and holistic paradigms of childbirth. International Journal of Gynecology \& Obstetrics, $75, \quad$ S5-S23. doi:http://dx.doi.org/10.1016/S0020-7292(01)00510-0

de Vignemont, F., \& Fourneret, P. (2004). The sense of agency: A philosophical and empirical review of the "who" system. Consciousness and Cognition, 13(1), 1-19.

Declercq, E., Labbok, M. H., Sakala, C., \& O'Hara, M. (2009). Hospital practices and women's likelihood of fulfilling their intention to exclusively breastfeed. American Journal of Public Health, 99(5), 929-935.

Dykes, F. (2006). Breastfeeding in Hospital: Mothers, Midwives and the Production Line. London, UK: Routledge.

Edwards, A., \& Elwyn, G. (2009). Shared decision-making in health care: Achieving evidence-based patient choice. In A. Edwards \& G. Elwyn (Eds.), Shared decisionmaking in health care: Achieving evidence-based patient choice (2nd ed., pp. 4-10). New York, NY: Oxford University Press.

Emanuel, E. J., \& Emanuel, L. L. (1992). Four Models of the Physician-Patient Relationship. JAMA: The Journal of the American Medical Association, 267(16), 2221-2226. doi:10.1001/jama.1992.03480160079038

Ewers, H. (2014). Postnatal care at crisis point. Retrieved from https://www.rcm.org.uk/news-views-and-analysis/news/postnatal-care-at-crisis-point

Gilbert, M. (2006). Rationality in Collective Action. Philosophy of the Social Sciences, 36(1), 3-17. doi:10.1177/0048393105284167

Heaton, J. (2004). Reworking Qualitative Data. Thousand Oaks, CA: Sage Publications. 
Hildingsson, I. M. (2007). New parents' experiences of postnatal care in Sweden. Women and Birth: the Journal of the Australian College of Midwives, 20, 105-113.

Hoddinott, P., Craig, L., Britten, J., \& McInnes, R. (2010). A prospective study exploring the early infant feeding experiences of parents and their significant others during the first 6 months of life: what would make a difference? August 2010 Retrieved from Edinburgh, UK:

Hoddinott, P., Craig, L. C. A., Britten, J., \& McInnes, R. M. (2012). A serial qualitative interview study of infant feeding experiences: idealism meets realism. BMJ Open, 2(2), e000504. doi:10.1136/bmjopen-2011-000504

Kukla, R. (2005). Mass Hysteria: Medicine, Culture, and Mothers' Bodies New York, NY: Rowman \& Littlefield

Labiner-Wolfe, J., Fein, S. B., Shealy, K. R., \& Wang, C. (2008). Prevalence of breast milk expression and associated factors. Pediatrics, 122, S63-S68. doi:10.1542/peds.2008$1315 \mathrm{~h}$

Langer, A., Schröder-Bäck, P., Brink, A., \& Eurich, J. (2009). The agency problem and medical acting: an example of applying economic theory to medical ethics. Medicine, Health Care and Philosophy, 12(1), 99-108. doi:10.1007/s11019-008-9138-y

Leeming, D., Williamson, I., Lyttle, S., \& Johnson, S. (2013). Socially sensitive lactation: Exploring the social context of breastfeeding. Psychology \& Health, 28(4), 450-468. doi:10.1080/08870446.2012.737465

Maynard, A., \& Bloor, K. (2003). Trust and performance management in the medical marketplace. JRSM, 96(11), 532-539. doi:10.1258/jrsm.96.11.532

McAndrew, F., Thompson, J., Fellows, L., Large, A., Speed, M., \& Renfrew, M. J. (2012). Infant Feeding Survey 2010. Retrieved from 
McDonald, K., Amir, L. H., \& Davey, M.-A. (2011). Maternal bodies and medicines: a commentary on risk and decision-making of pregnant and breastfeeding women and health professionals. BMC Public Health, 11(5), 1-8. doi:10.1186/1471-2458-11-s5-s5

McMullan, M. (2006). Patients using the Internet to obtain health information: How this affects the patient-health professional relationship. Patient Education and Counseling, 63(1-2), 24-28. doi:http://dx.doi.org/10.1016/j.pec.2005.10.006

Moran, F. M. (1993). Subject and agency in psychoanalysis: Which is to be master? New York, NY: New York University Press.

Morgan, M. (1997). The Doctor-patient relationship. In G. Scambler (Ed.), Sociology as Applied to Medicine (4th ed., pp. 47 - 62). London, UK: W.B. Saunders.

O'Brien, M., Buikstra, E., Fallon, T., \& Hegney, D. (2009a). Exploring the Influence of Psychological Factors on Breastfeeding Duration, Phase 1: Perceptions of Mothers and Clinicians. Journal of Human Lactation, 25(1), 55-63. doi:10.1177/0890334408326071

O'Hair, D., Villagran, M. M., Wittenberg, E., Brown, K., Ferguson, M., Hall, H. T., \& Doty, T. (2003). Cancer Survivorship and Agency Model: Implications for Patient Choice, Decision Making, and Influence. Health Communication, 15(2), 193-202. doi:10.1207/s15327027hc1502_7

O’Brien, M. L., Buikstra, E., Fallon, T., \& Hegney, D. (2009b). Strategies for success: a toolbox of coping strategies used by breastfeeding women. Journal of Clinical Nursing, 18(11), 1574-1582. doi:10.1111/j.1365-2702.2008.02667.x

Oakley, L. L., Renfrew, M. J., Kurinczuk, J. J., \& Quigley, M. A. (2013). Factors associated with breastfeeding in England: an analysis by primary care trust. BMJ Open, 3(e002765). doi:10.1136/bmjopen-2013-002765

Pacherie, E. (2007). The sense of control and the sense of agency. PSYCHE 13(1), 1-30. 
Pope, C., Ziebland, S., \& Mays, N. (2000). Analysing qualitative data. BMJ, 320(7227), 114116. doi:10.1136/bmj.320.7227.114

Rayner, J.-A., Forster, D., McLachlan, H., Yelland, J., \& Davey, M.-A. (2008). A state-wide review of hospital postnatal care in Victoria, Australia: The views and experiences of midwives. $\quad$ Midwifery, $\quad$ 24(3), 310-320. doi:http://dx.doi.org/10.1016/j.midw.2006.10.008

Redshaw, M., \& Henderson, J. (2012). Learning the Hard Way: Expectations and Experiences of Infant Feeding Support. Birth, 39(1), 21-29. doi:10.1111/j.1523536X.2011.00509.x

Renfrew, M., Craig, D., Dyson, L., McCormick, F., Rice, S., King, S., \& al., e. (2009). Breastfeeding promotion for infants in neonatal units: A systematic review and economic analysis. Health Technol Assess, 13(40), 1-146. doi:10.3310/hta13400

Rodney, P., Brown, H., \& Liashenko, J. (2006). Moral agency: Relational connections and trust. In J. L. Storch, P. Rodney, \& R. Starzomski (Eds.), Toward a moral horizon: nursing ethics for leadership and practice (pp. 154-177). Toronto, ON: Pearson Prentice Hall.

Rollins, N. C., Bhandari, N., Hajeebhoy, N., Horton, S., Lutter, C. K., Martines, J. C., . . . Victora, C. G. (2016). Why invest, and what it will take to improve breastfeeding practices? Lancet, 387, 491-504. doi:http://dx.doi.org/10.1016/S0140$\underline{6736(15) 01044-2}$

Rothchild, J., Van Cleve, H., Mumford, K., Claire, E., \& Johnson, M. A. (2016). "BabyFriendly" or "Mother-Hostile"?: Deconstructing Gender in Breastfeeding Advocacy Campaigns. In R. Badruddoja \& M. Motapanyane (Eds.), “New Maternalisms”: Tales of Motherwork (Dislodging the Unthinkable) (pp. 140-153). Bradford, ON: Demeter Press. 
Salmon, J. W., White, W., \& Feinglass, J. (1990). The futures of physicians: Agency and autonomy reconsidered. Theoretical Medicine and Bioethics, 11(4), 261-274. doi:10.1007/bf00489817

Schmied, V., Beake, S., Sheehan, A., McCourt, C., \& Dykes, F. (2011). Women's Perceptions and Experiences of Breastfeeding Support: A Metasynthesis. Birth, 38(1), 49-60. doi:10.1111/j.1523-536X.2010.00446.x

Schmied, V., Cooke, M., Gutwein, R., Steinlein, E., \& Homer, C. (2009). An evaluation of strategies to improve the quality and content of hospital-based postnatal care in a metropolitan Australian hospital. Journal of Clinical Nursing, 18(13), 1850-1861. doi:10.1111/j.1365-2702.2008.02746.x

Schmied, V., \& Lupton, D. (2001). Blurring the boundaries: Breastfeeding and maternal subjectivity. Sociology of Health \& Illness, 23(2), 234-250. doi:10.1111/14679566.00249

Shapiro, S. P. (2005). Agency theory. Annual Review of Sociology, 31(1), 263-284. doi:10.1146/annurev.soc.31.041304.122159

Sidani, S. (2011). Self-care. In D. Doran (Ed.), Nursing outcomes: The state of the science (2nd ed., pp. 79-130). Sudbury, MA: Jones \& Bartlett Learning.

Sousa, V. D., Zauszniewski, J. A., Musil, C. M., Price Lea, P. J., \& Davis, S. A. (2005). Relationships Among Self-Care Agency, Self-Efficacy, Self-Care, and Glycemic Control. Research and Theory for Nursing Practice, 19(3), 217-230.

Street Jr, R. L., Makoul, G., Arora, N. K., \& Epstein, R. M. (2009). How does communication heal? Pathways linking clinician-patient communication to health outcomes. Patient Education and Counseling, 74(3), 295-301. doi:10.1016/j.pec.2008.11.015 
Sweet, L. (2008). Birth of a very low birth weight preterm infant and the intention to breastfeed 'naturally'. Women and birth : journal of the Australian College of Midwives, 21(1), 13-20. doi:10.1016/j.wombi.2007.11.001

Thomson, G., Dykes, F., Hurley, M. A., \& Hoddinott, P. (2012). Incentives as connectors: insights into a breastfeeding incentive intervention in a disadvantaged area of NorthWest England. BMC Pregnancy and Childbirth, 12(1), 1-13. doi:10.1186/1471-2393$12-22$

Thomson, G., Ebisch-Burton, K., \& Flacking, R. (2015). Shame if you do - shame if you don't: women's experiences of infant feeding. Maternal \& Child Nutrition, 11(1), 3346. doi:10.1111/mcn. 12148

UNICEF. (2010). UNICEF UK, Baby Friendly Initiative. 2010: Hospital initiative review 2010. Retrieved from http://www.unicef.org.uk/BabyFriendly/News-and$\underline{\text { Research/News/Hospital-Initiative-Review---Final-document-now-available/ }}$

Victora, C. G., Bahl, R., Barros, A. J. D., França, G. V. A., Horton, S., Krasevec, J., . . . Rollins, N. C. (2016). Breastfeeding in the 21st century: epidemiology, mechanisms, and lifelong effect. Lancet, 387, 475-490. doi:http://dx.doi.org/10.1016/S0140$\underline{6736(15) 01024-7}$

Volk, A. A. (2009). Human breastfeeding is not automatic: Why that's so and what it means for human evolution. Journal of Social, Evolutionary and Cultural Psychology, 3(4), 305-314. doi: http://dx.doi.org/10.1037/h0099314

Williamson, I., Leeming, D., Lyttle, S., \& Johnson, S. (2012). It should be the most natural thing in the world': exploring first-time mothers' breastfeeding difficulties in the UK using audio-diaries and interviews. Maternal and Child Nutrition, 8(4), 434-447. doi:10.1111/j.1740-8709.2011.00328.x 